\title{
STEREOLOGY FROM ONE OF ALL THE POSSIBLE ANGLES
}

\section{LESZEK WOJNAR}

Institute of Materials Science, Cracow University of Technology, Al. Jana Pawła II 27, 31-864 Cracow, Poland e-mail: fotobit@fotobitlw.com

(Accepted October 8, 2002)

\begin{abstract}
Relation between image analysis and stereology is discussed in terms of different fields of applications, especially materials science, biology and medicine. Some long-term tendencies observed as well as possible future trends are discussed. The need of a wider use of image analysis techniques including mathematical morphology in any field of science is demonstrated. Simultaneously, the significance of stereological background in automatic quantification of the investigated structures is confirmed.
\end{abstract}

Keywords: automation, biology, image analysis, image processing, materials science, medicine, stereology.

\section{INTRODUCTION}

Since two years Acta Stereologica, the official journal of the International Society for Stereology, has a new name, Image Analysis and Stereology. I was among those voting for this change. Independently, the last ISS meeting in Bordeaux (Proc. $8^{\text {th }}$ ECS\&IA, 2001) was organized under the name of $8^{\text {th }}$ European Congress for Stereology and Image Analysis. The Polish Society for Stereology (PSS), which organizes under the auspices of ISS a series of international conferences known as STERMAT (STEReology in MATerials Science), took the same decision. The last conference in the series, held in Cracow, was called $6^{\text {th }}$ International Conference on Stereology and Image Analysis in Materials Science (Proc. STERMAT, 2000).

Taking into account the above mentioned facts this seems to be natural to discuss relation between image analysis and stereology in the past and today. Nearly 20 years of attending both ISS and PSS conferences gives me enough material for thorough analysis of such a type. Since the congress in Caen (7ICS, 1987) I have commented various events and tendencies within our Society using humorous cartoons (Fig. 1). In most cases these drawings were used in collaboration with Jean-Louis Chermant, one of the past Presidents of ISS. So, this paper can be treated as the next part of the paper published in 1992 (Chermant and Wojnar, 1992).

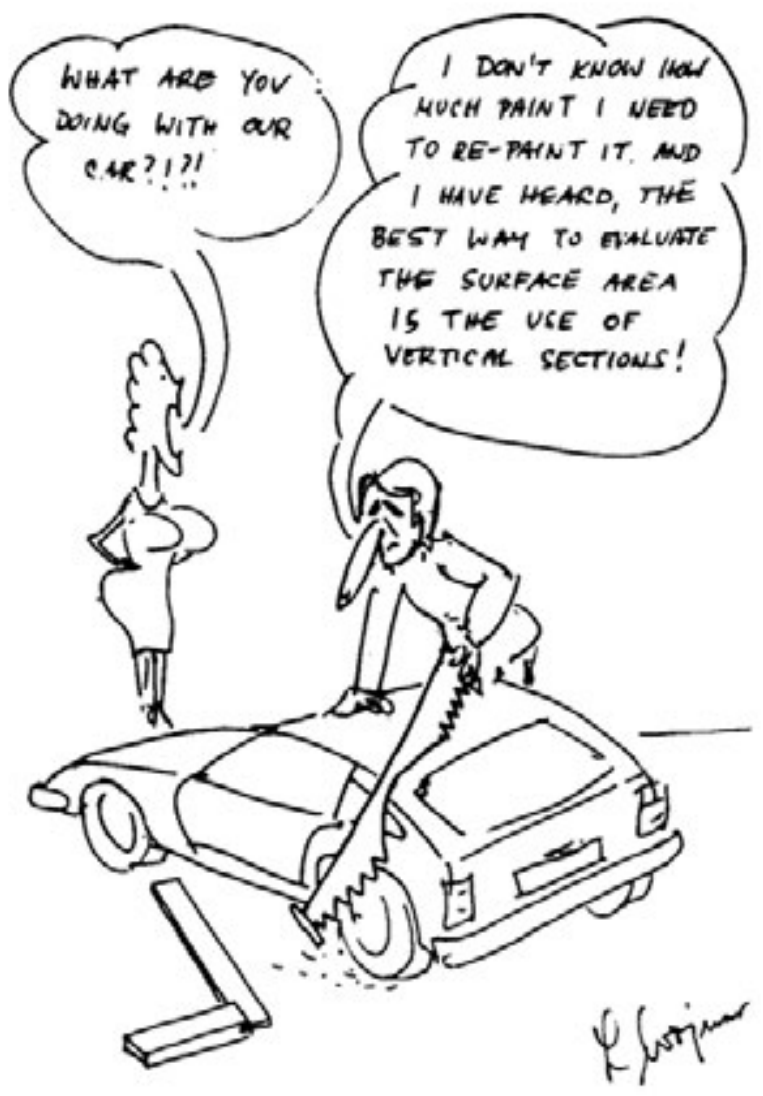

Fig. 1. Application of the method of vertical sections - opening illustration of the Proceedings of $7^{\text {th }}$ ISS Congress in Caen, 1987. 


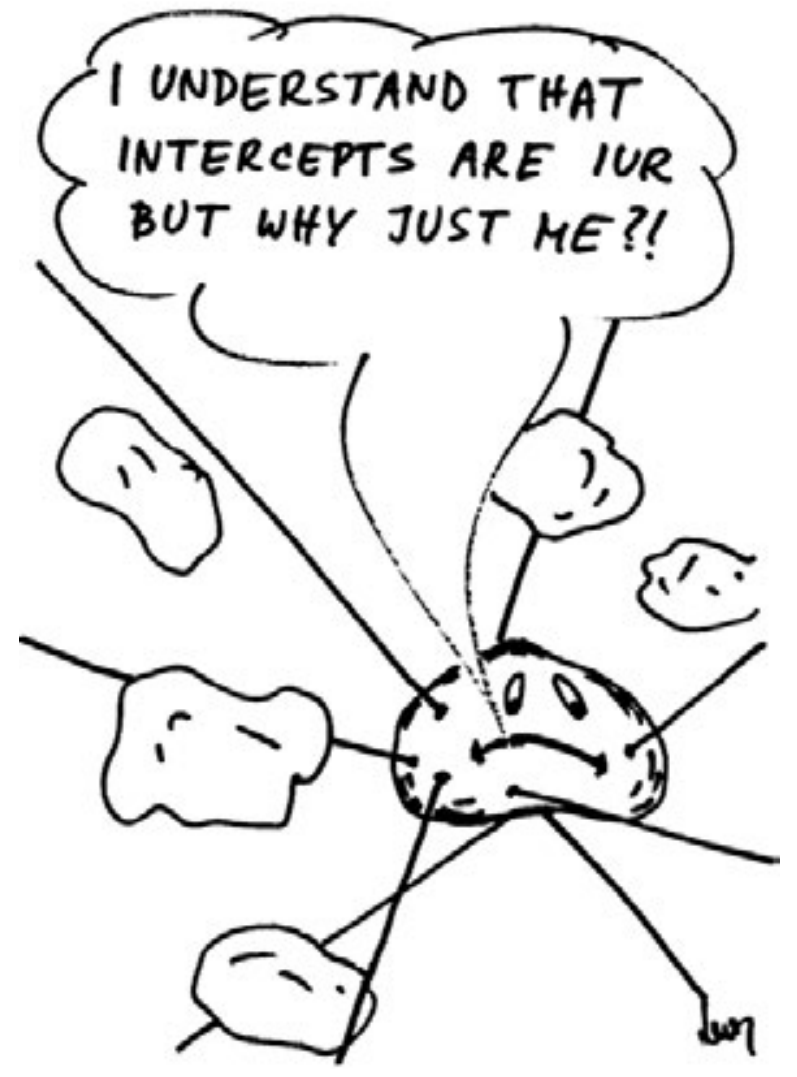

Fig. 2. The uniformity, independency and randomness are not necessarily quite obvious and easy for application.

The sense of humor is present in our society since many years. For example, in late eighties the Board distributed T-shirts with the ISS logo surrounded by the following text: Stereologists do it from all the possible angles. In that context my remarks are, obviously, done from a single angle or point only (compare Fig. 2) and should be understood as a part of discussion on the future of the International Society for Stereology. The title of this paper expresses also my awareness that some readers can disagree with some of the opinions presented.

\section{WHAT IS STEREOLOGY AND IMAGE ANALYSIS?}

The term stereology is relatively well defined. However, at least a few equivalent definitions can be found (Weibel, 1987):
Probably the most precise one is definition I: "Stereology is a body of procedures, mainly geometrico-statistical, which have the aim of obtaining information about three-dimensional structure from two-dimensional, flat images".

In a simplified, more consistent form the above description can be put as definition II: "It (stereology) can also be defined as extrapolation from two- to three-dimensional space".

In turn, the most descriptive and intuitive one seems to be definition III, related to biological and medical applications: "The stereologist measures and counts the profiles of the cut tissue elements within a slice, and from the data thus obtained he draws conclusions about the geometrical properties of the original, three-dimensional objects".

Unfortunately, we have no such precise definition of image analysis. In many works devoted to this problem the term image analysis is treated as if this was absolutely obvious. This can lead to some misinterpretation, especially if we use similar terms, like, for example, image processing or image understanding (Coster and Chermant, 1989; Russ, 1995; Serra, 1982; Sonka et al., 1998; Wojnar, 1998). Therefore we need possibly good and universal definitions of these basic terms.

First, we should define an image. Probably we have a good intuitive understanding of this term, however, a more formal description seems to be necessary. In ASTM Standards on can find the following definition: "Image - a representation of an object produced by means of radiation, usually with a lens or mirror system" (ASTM, 1999). However, for our considerations a little bit wider and more intuitive definition is proposed: "An image is any set of information which can be captured using optical and vision systems, like, for example, human vision system or photo camera. Electronic representation of such information, used in computer systems and digital cameras, is also understood as an image." Accordingly to this definition "image" can be also a piece of material containing any drawing or picture. Nevertheless, the most important is its ability to store some information. 


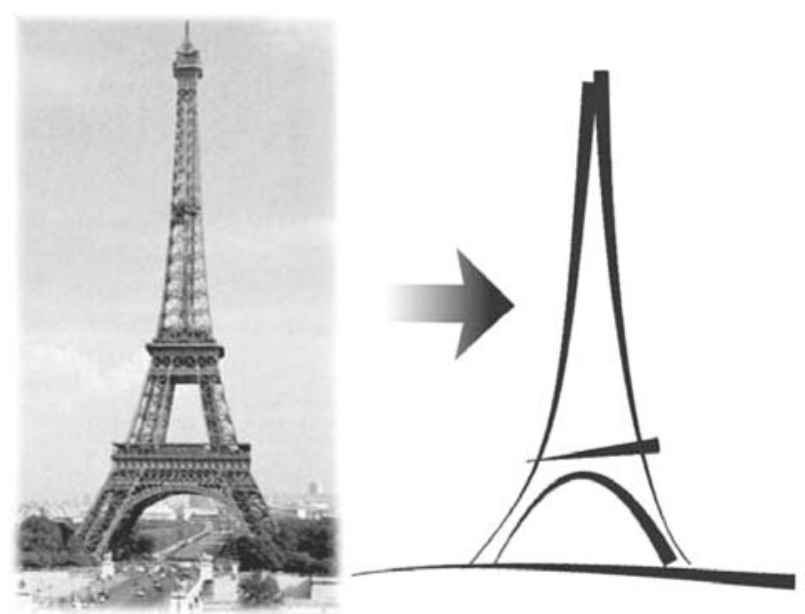

Fig. 3. Image processing converts an image (or a series of images) into another image (or a series of images).

Consequently, we can define image processing as a process of data (information) transformation in which both, initial and final set of information are images or series of images (Fig. 3). Further, image analysis would be a process of data (information) transformation in which an image (or a series of images) is transformed into another set of information, which is not an image (see Fig. 4). In such circumstances image processing can be a part of image analysis.

Image analysis can be used for different purposes: documentation (maps and plans), guiding missiles, monitoring the movement, scientific research, etc. Quite often researchers applying stereological tools use image analysis only for extraction of some morphological information from the objects, which can be detected in the image. When such objects are impossible to be precisely detected image analysis tools are often rejected as useless (Weibel, 1987) .

This is clearly visible in Fig. 4 that image analysis can lead to different, equally correct solutions. The sentence: "this is the Eiffel tower" informs that the drawing represents the Eiffel tower whereas the second answer stresses the fact that this drawing is strongly simplified. Another interesting observation can be drawn out from discussion of the results of analysis of Fig. 5. If we ask some people, what they see in this image, we can get the following answers (this set is not exhaustive):

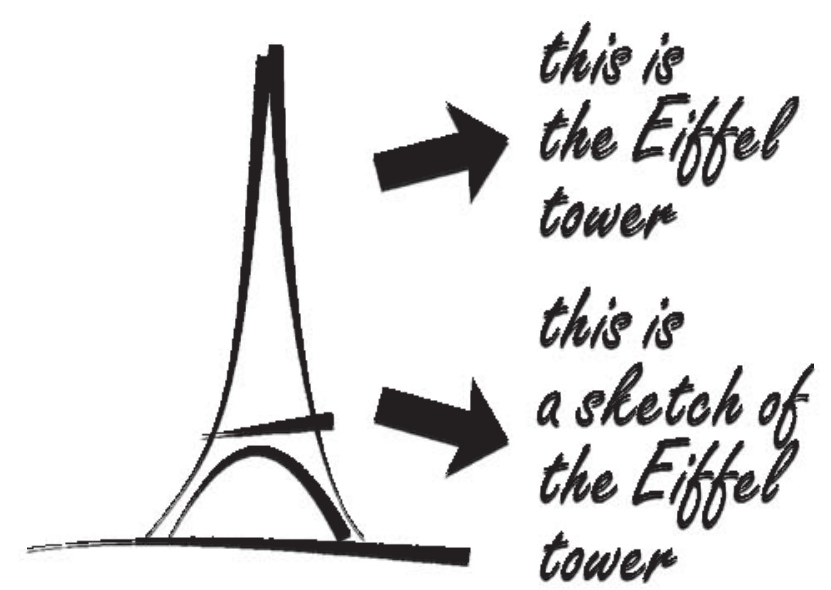

Fig. 4. Image analysis converts an image (or a series of images) into another set of information that is not an image.

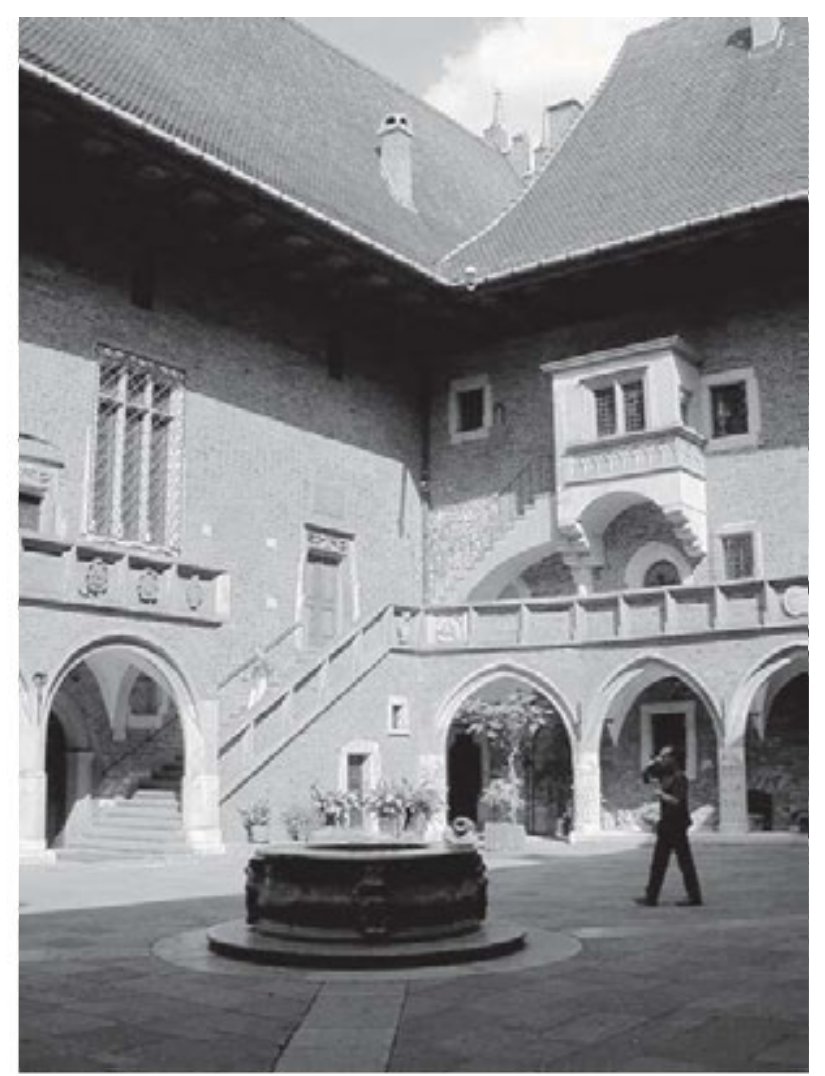

Fig. 5. After analysis of this image some people can tell us the time at which the photograph was taken. 


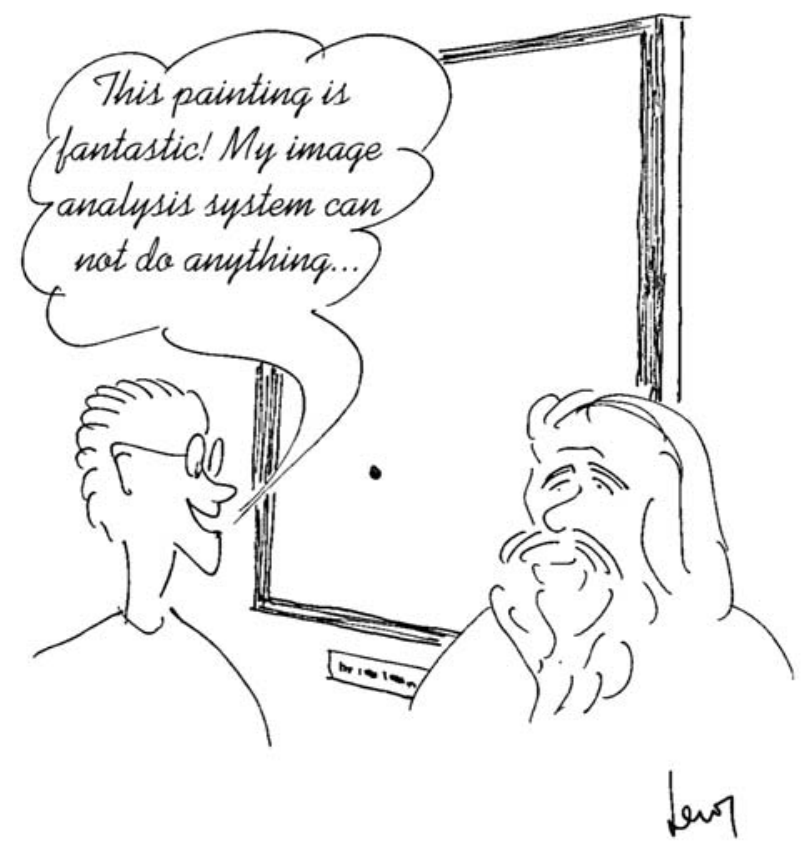

Fig. 6. Image analysis cannot solve all our research problems.

- We see an internal court (most people can give this answer).

- This court is dated to the XIV or XV c. (less people are capable to give this answer).

- This is Collegium Maius in Cracow, Poland (only people interested in history or architecture and those who visited Cracow can give this answer).

- This is a part of one of the oldest universities in Europe (this answer is reserved to an even smaller group of people).

All these answers seem to be clear but probably a few people could give us a very surprising one:

- This picture was taken in the afternoon, possibly in May, June or July.

Let we analyze now more deeply this last one that seems to be somewhat strange. Indeed, this image gives no information concerning time. However, someone can memorize location of this building and decide that the camera was oriented in Northeast direction.
So, after analysis of the shade one can decide that this picture was taken in the afternoon. Moreover, there are some arguments that this was late spring or beginning of the summer (on the basis of some angles in the shade and the presence of flowers).

From the above example we see that the result of image analysis process highly depends on our knowledge. This explains why this method is so difficult for automation, i.e., computer aided image analysis (Fig. 6). Contemporary software for image analysis offers numerous image processing operations and tools capable to extract numerical descriptors from different objects in the image but preparation of appropriate algorithms is still difficult. Moreover, we can only rarely find works in which full algorithms are explained in details (Wojnar, 1998; Szala, 2001). Even if the whole process of image processing and data extraction is successful, correct data interpretation arises as a new, significant problem (Coster and Chermant 1989; Chaix et al., 1992; Pirard, 1992; Stroeven and Stroeven, 1992; Wojnar and Kurzydłowski, 2000).

\section{Rotator or nucleator... That is the question!}

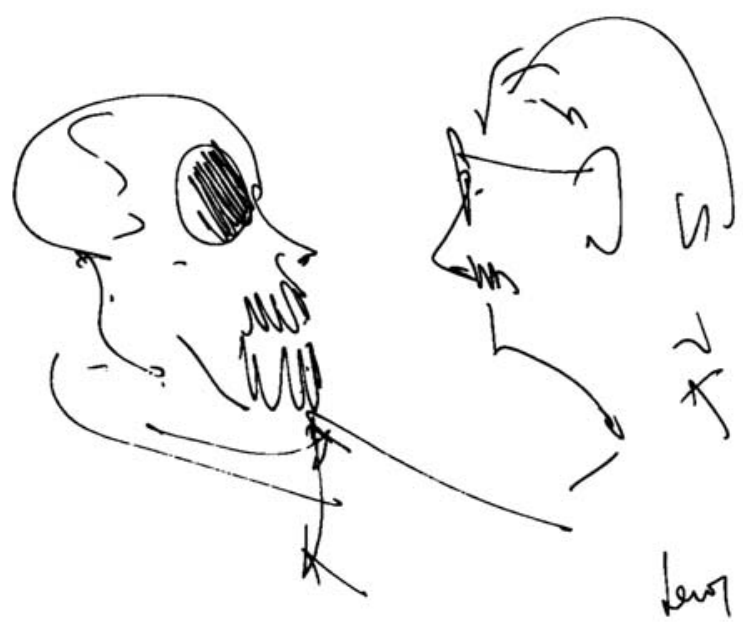

Fig. 7. Hamlet-type stereological problem illustrates subtle differences between various modern stereological tools (9ICS, Copenhagen, 1995). 


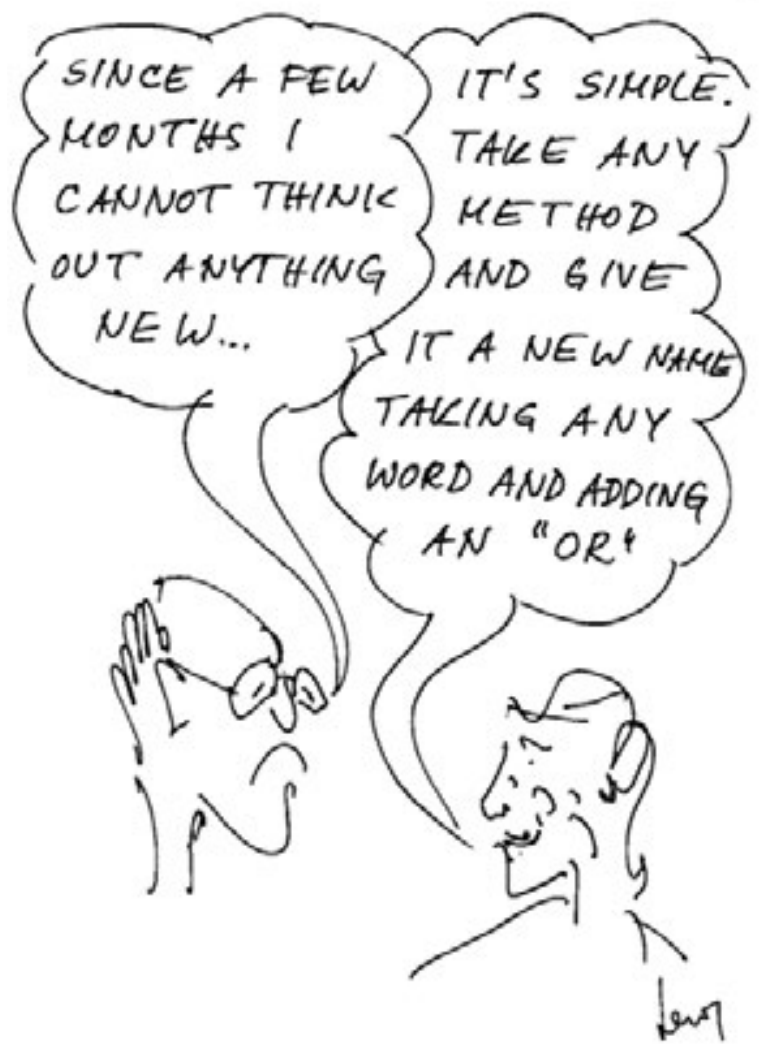

Fig. 8. Probably this drawing was a little bit too much satiric (9ICS, Copenhagen, 1995).

\section{STEREOLOGY VERSUS IMAGE ANALYSIS}

In late eighties and early nineties a rapid growth in the number of new stereological tools was observed, especially in the field of biology and medicine (Gundersen et al., 1988a, b). The Danish group of stereologists introduced an overall name for these routines - second order stereology. The multitude of methods introduced has lead to some humorous and not necessarily very courteous drawings, prepared during the ISS Congress in Copenhagen, (9ICS, 1995) (Figs. 7-9). Some of these tools have found application in analysis of images taken using confocal microscopy what helped to introduce some interaction with computer methods (Janacek 1999). One can also find applications of these methods in materials science (Stroven and Stroeven 1992, Kurzydlowski and Ralph 1995).
Parallel, the development of mathematical morphology has led to automatic applications of image analysis. One can quote, for example, the common work of the Laboratory of Histochemistry and Cytochemistry at the University of Leiden, The Netherlands, and the Center for Mathematical Morphology, Ecole de Mines de Paris at Fontainebleau, France, in the years 1976-1985. They got a kind of "European contract", financed by the Federal Republic of Germany, via Leitz-Wetzlar, devoted to automatic detection of cytological specimens. The cancerous cells were analyzed and extracted automatically using the Leitz TAS (Texture Analysis System). Very successful results were obtained proving that the use of mathematical morphology and automatic image analysis are important tools in all the sciences, from materials science to biology and medicine (GoyartsBeldstra, 1983).

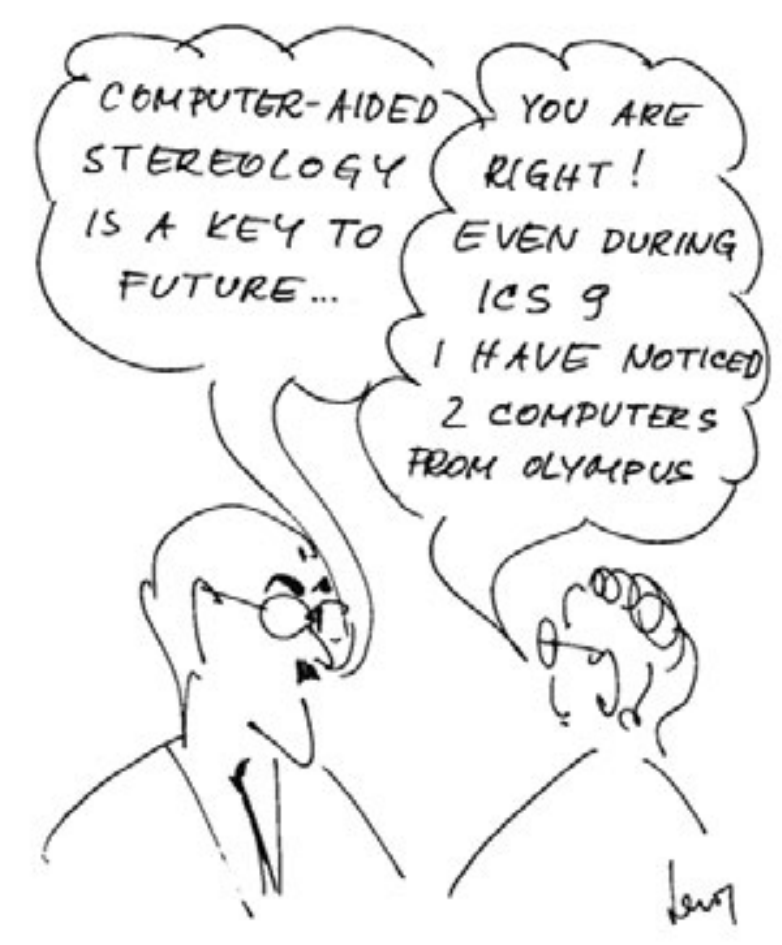

Fig. 9. New stereological methods have been fully manual ones, initially without any support from computational methods (9ICS, Copenhagen, 1995). 


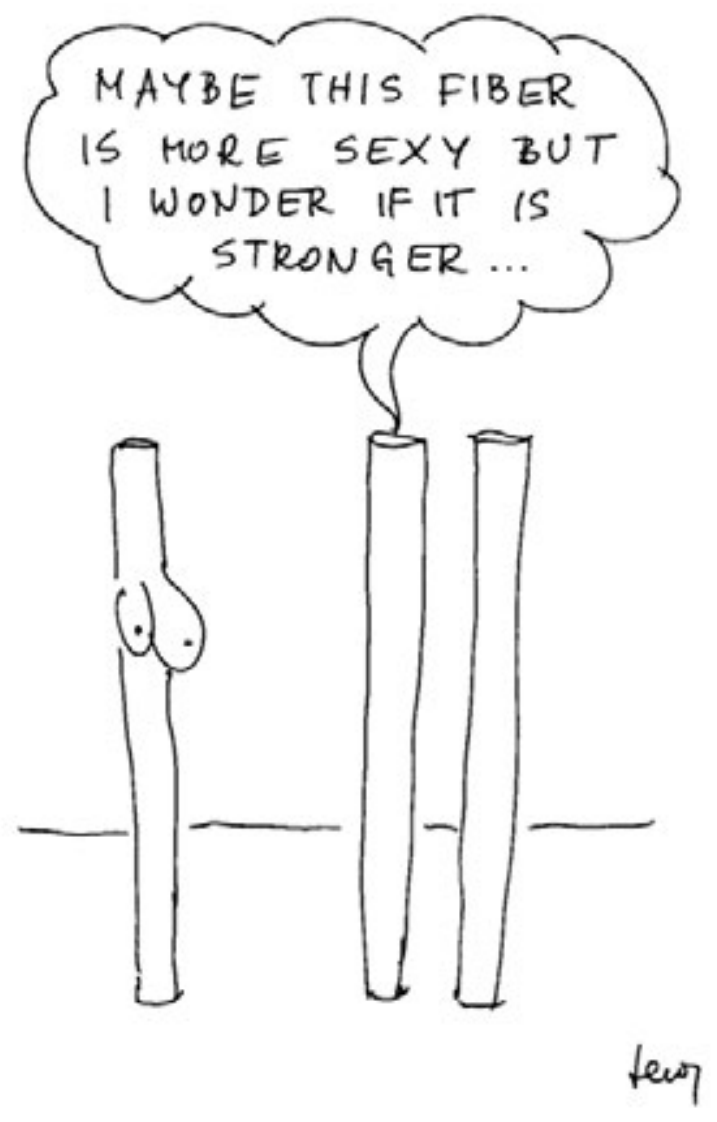

Fig. 10. This was a big challenge to find something humorous for ceramic fibers. However, this problem is important for the damage mechanism.

Numerous research groups widen applications of image analysis (Figs. 10 and 11). Jean-Louis Chermant and his group were concentrated on ceramic matrix composites and other engineering materials (Chermant, 1989) and the Center for Mathematical Morphology at Fontainebleau developed new image analysis tools for various applications (Serra, 1988). Jeulin has developed Poisson models that are random closed sets and follow classical laws of the theory of probability. These models found various applications in modeling and image analysis (Jeulin, 1992a,b). Polish stereologists worked in this time on development of objective guidelines for automation of stereological analysis supported by image analysis methods (Kurzydłowski and Ralph 1995; Cwajna et al., 1997a,b). This list is, obviously, not exhaustive. Possibly one can state that these successful applications refer mainly to materials science. Full automation in the field of biology and medicine is much more difficult due to the complexity of images analyzed. The author has faced this problem in his own research (Gądek et al., 2000; Wojnar et al., 2000; Tęsiorowski et al., 2001) and understand all the reservations. Nevertheless, the results of the latest works are quite promising and, what seems to be even more important, demonstration of the power of the newest solutions caused that many physicians are really opened for applications of image analysis as a supplementary tool in diagnostics.

The nineties were marked by enormous growth in computational power of microcomputers. As a consequence, good quality software for image analysis was marketed (Aphelion from ADCIS, Image Pro Plus from Media Cybernetics, LUCIA from Imaging Laboratory, Visilog from Noesis, etc.). Application of new image analysis techniques allowed freshening areas that seemed to be very old and completely exploited (Fig. 12). Modern optical microscopes, equipped with infinity-corrected optics that offer better brightness and contrast of the images as well as reduced effect of nonuniform illumination usually are supplied with high quality digital cameras. All these technological innovations allowed for wider introduction of new observation techniques, like, for example, epifluorescence methods. Consequently, one observes unprecedented growth in application of image processing (for improving the initial image quality) and image analysis tools.

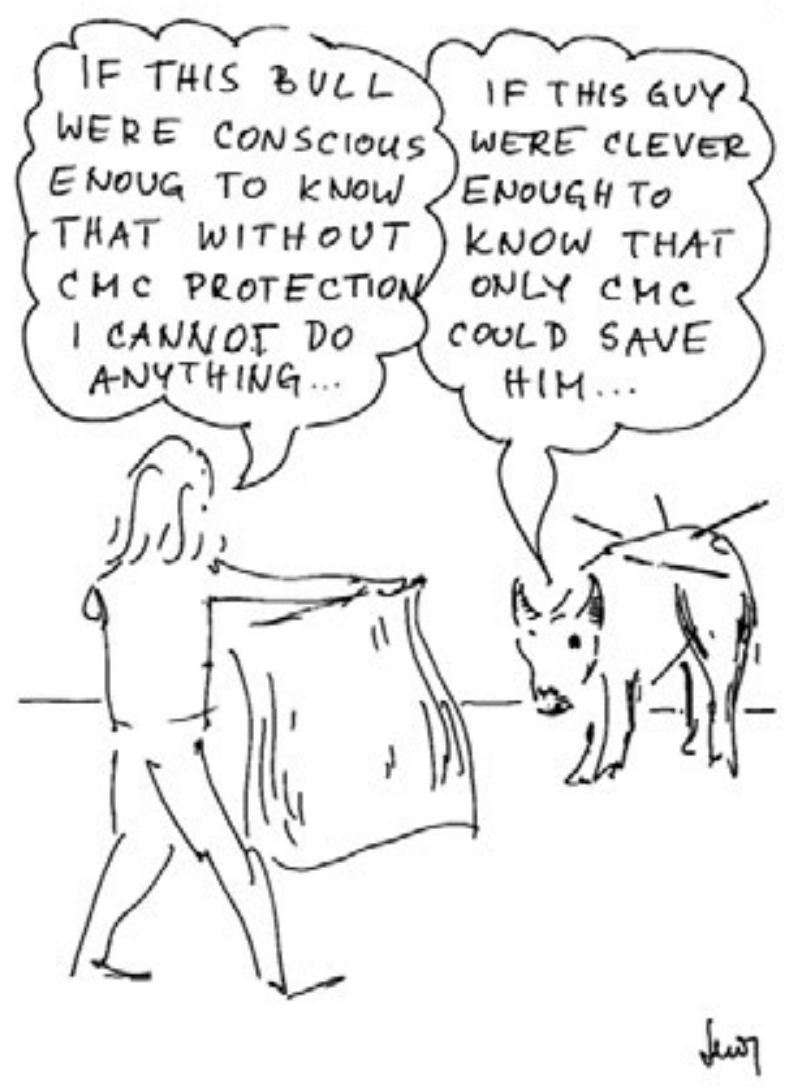

Fig. 11. Sometimes the result was quite interesting. 


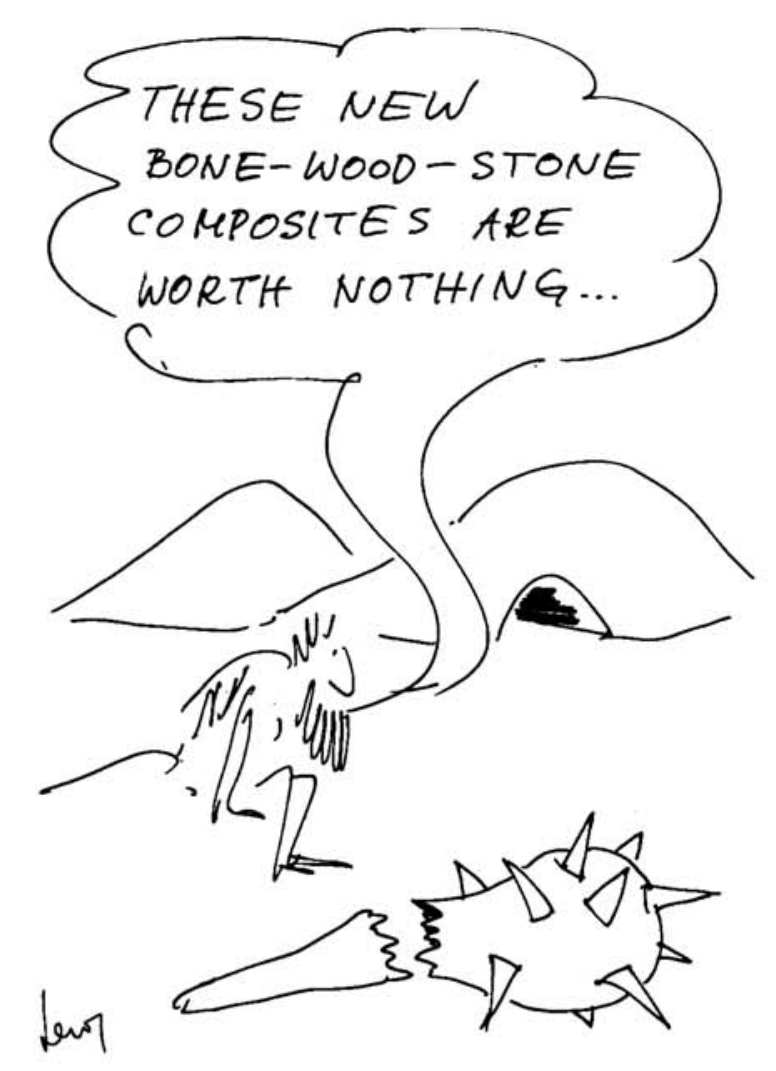

Fig. 12. This is probably one of my best cartoons (7ICS, Caen, 1987).

This seems to be interesting to analyze how the above-mentioned processes were reflected in proceedings of international conferences. Analysis of congresses organized by International Society for Stereology shows a surprising tendency to lower the amount of works devoted to application of image analysis (Fig. 13). This is possibly a long-time effect of some fears, clearly expressed (Weibel, 1987) by the following words: "The technological trend towards automatic image analysis has had unfortunate effects on the technological advancement of stereological tools. (...) As a consequence the market now offers a host of expensive image analyzers which do not make use of the best of stereology". Fortunately, contemporary image analysis tools are approxi-mately one order of magnitude cheaper and significantly more user-oriented.

Analysis of works related to stereology but restricted to congresses organized under the auspices of ISS gives no objective information concerning the methods applied. Many researchers using automatic image analysis publish their works outside this framework. Nevertheless, analysis of the ratio between works related or not to automatic image analysis we discuss here is important for the future of stereology. The observed tendency to avoid automation in stereological analysis was dramatically changed during the last meeting in Bordeaux (8ECS\&IA, 2001), probably thanks to numerous works devoted to remote sensing and applications often initiated by military ones (Fig. 14). One should also keep in mind that the majority of participants in every international conference belong to the country in which the meeting is held. In addition, this observation allows for approximate judgment of the main directions of scientific activity of the organizers.

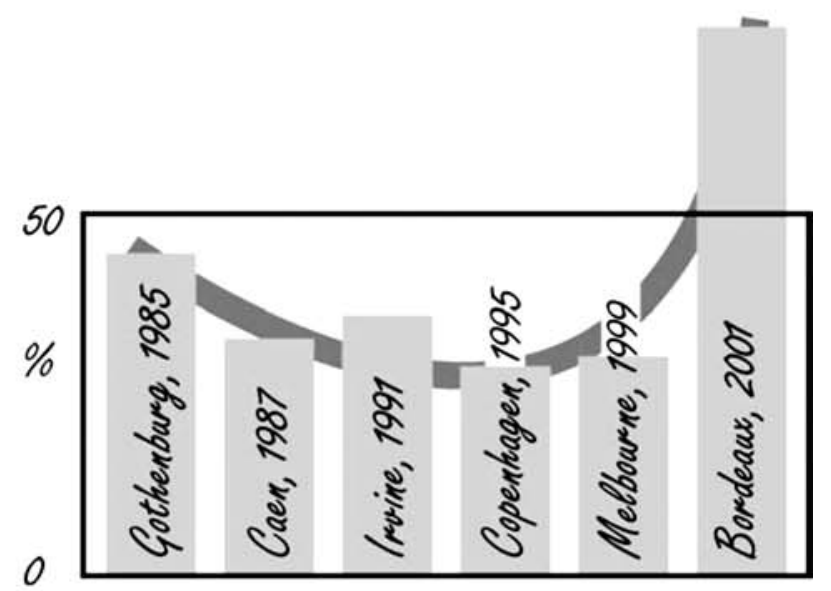

Fig. 13. Fraction of papers devoted to or using image analysis methods in proceedings of International and European congresses of ISS.

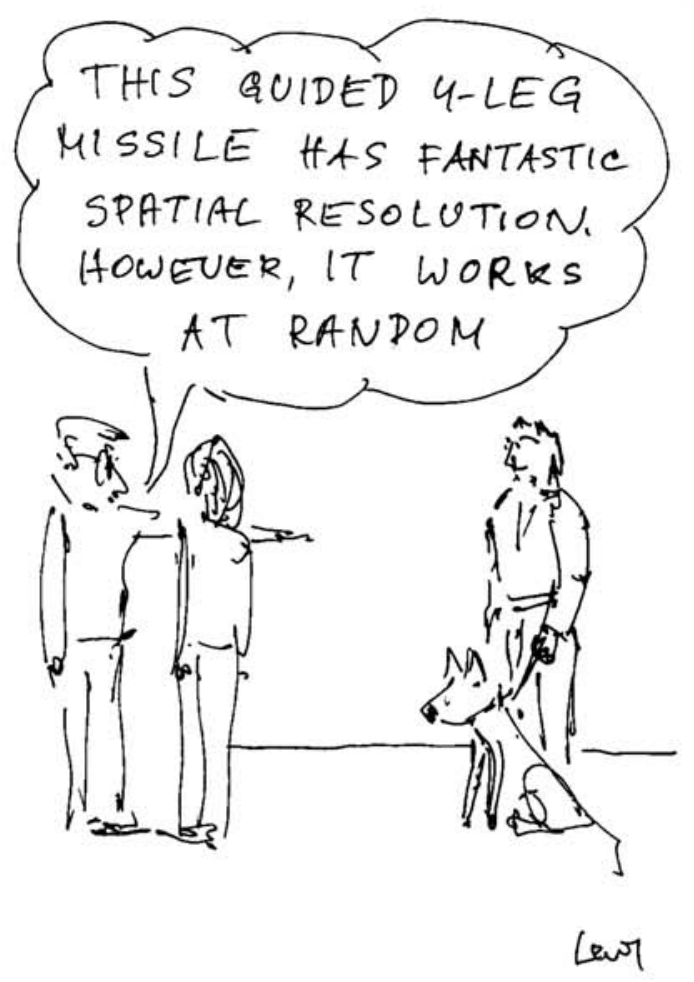

Fig. 14. During the congress in Bordeaux many applications of image analysis were presented and the building was guarded from the evenings by men with dogs (8ECS\&IA, 2001). 
The above remarks on the role of the local community can explain an inverse tendency that we observe in the series of STERMAT conferences, founded in 1983 and devoted to applications in materials science (Fig. 15). During the last meeting (STERMAT'2000, Cracow) more than half of the works discussed or at least applied image analysis techniques. A significant "jump" observed in 1994 can be explained by the already mentioned introduction of relatively inexpensive software-based image analyzers.

Obviously, appropriate scientific level of contributions is not the only problem of the organizers. We have met quite difficult moments during the third STERMAT, held in 1990 at Szczyrk. The second day of the conference was the date of Germany reunification. The atmosphere became very dense due to the PolishGerman history but, fortunately, humorous explanation of this historical moment as simple image processing operations, based on tracing a pseudo-geodesic path on the map of Central Europe (Figs. 16, 17) helped to solve the problem.

The last ISS Congress in Bordeaux opened a serious discussion on the interaction between stereology and image analysis. If one comes back to the definitions, than will see that stereology was developed for "obtaining information about three-dimensional structure from two-dimensional, flat images". This is in perfect agreement with the definition of image analysis as a "process of data transformation in which an image is transformed into another set of information". In such circumstances this is obvious that any conflict between classical stereology and image analysis is purely academic and artificial as these methods do the same tasks, growing from the same theoretical background, based on mathematics and geometrical probability (Kendall and Moran 1963; Santalo 1976) (Fig. 18).

\section{CURRENT STATUS}

So, currently this seems to be very important to come back to close cooperation of specialists in both, image analysis and theoretical stereology. A lack of good theoretical background, concerning, for example, correct sampling procedures (Fig. 19) can lead to serious, systematic errors. Some of them can be observed in standardized methods for grain size assessment (Wojnar, 1998). Deep analysis of various methods of analysis has proven that automatic methods are approximately 100 times faster, give more consistent, free of the human factor, results and more data than manual quantification, for example, grain size distribution (Latała and Wojnar, 2001).

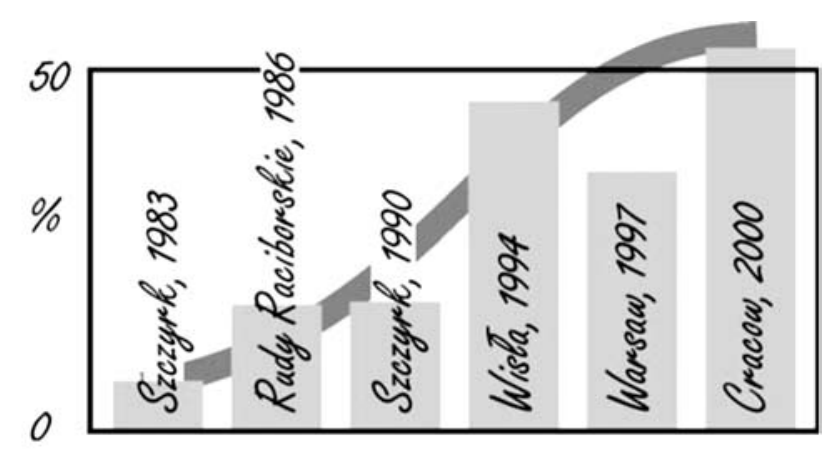

Fig. 15. Fraction of papers devoted to or using image analysis methods in proceedings of STERMAT conferences in Poland (this series is international since 1990).

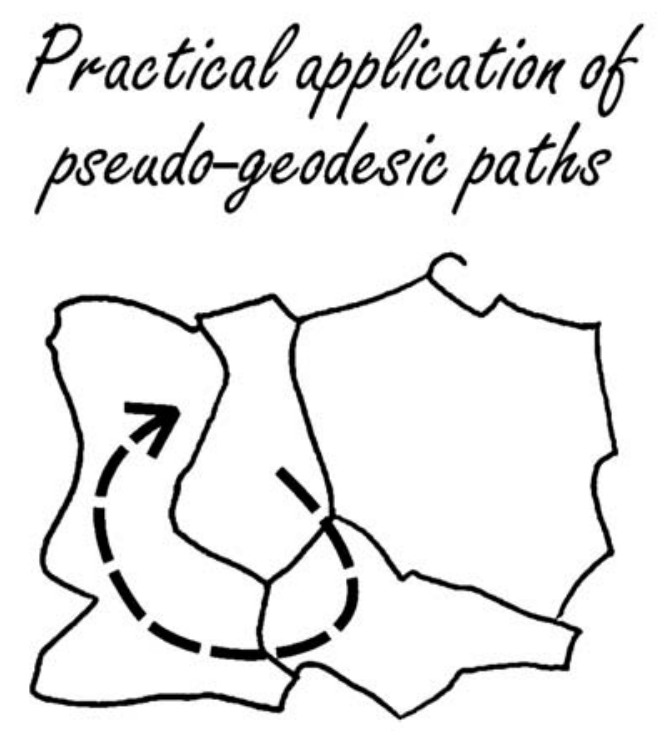

Fig. 16. Massive migration from East to West Germany through Czechoslovakia in 1989 was interpreted as detection of a pseudo-geodesic path (STERMAT'90).

In medical applications new diagnostic tools, like computer tomography, have built-in procedures for image restoration and processing. Without these techniques, development of new diagnostic tools would be impossible. Moreover, image analysis methods can be successfully applied in traditional diagnostic methods. Lack of automation during stereological examination leads to careless quantification of massive diagnostic material. This can introduce serious errors. Moreover, modern visualization and specimen preparation techniques allows for obtainment of good quality biological images suitable for fully automatic or at least semi-automatic analysis. Image processing is currently widely used in radiography and computer aided tomography would be simply impossible without 
image analysis (Muche et al., 2000; Udupa and Herman, 2000; Gądek et al., 2001; Wojnar et al., 2001).

\section{CONCLUSIONS}

1. This seems to be clear that image analysis, mathematical morphology and stereology use very similar theoretical background and perform basically the same tasks.

2. Image analysis without thorough stereological background can lead to misinterpretation of the results or, what is even more dangerous, to highly biased quantification of features to be analyzed.

3. Avoiding application of image analysis methods in stereological analysis can lead to less objective quantification and dramatically slows down the speed of analysis. In an indirect way this can lead to deterioration of the quality of obtained results.

\section{A pronciple of stermatting}

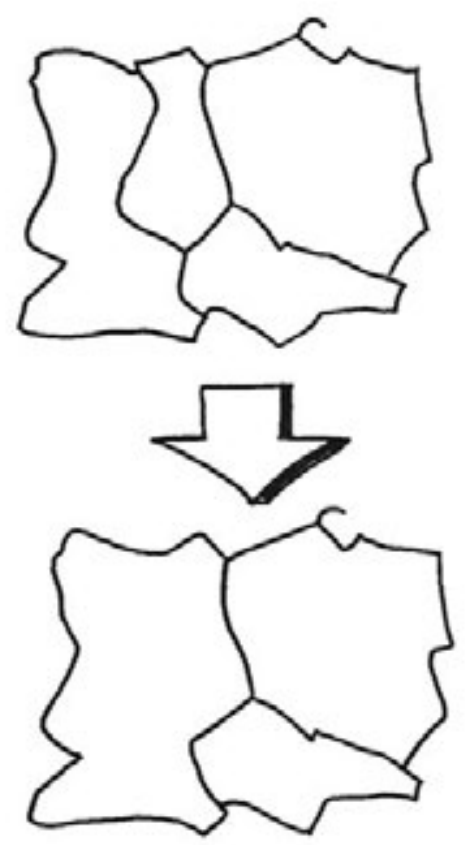

Fig. 17. Unification of two parts of Germany was shown as a simple morphological operation on the map (STERMAT'90).

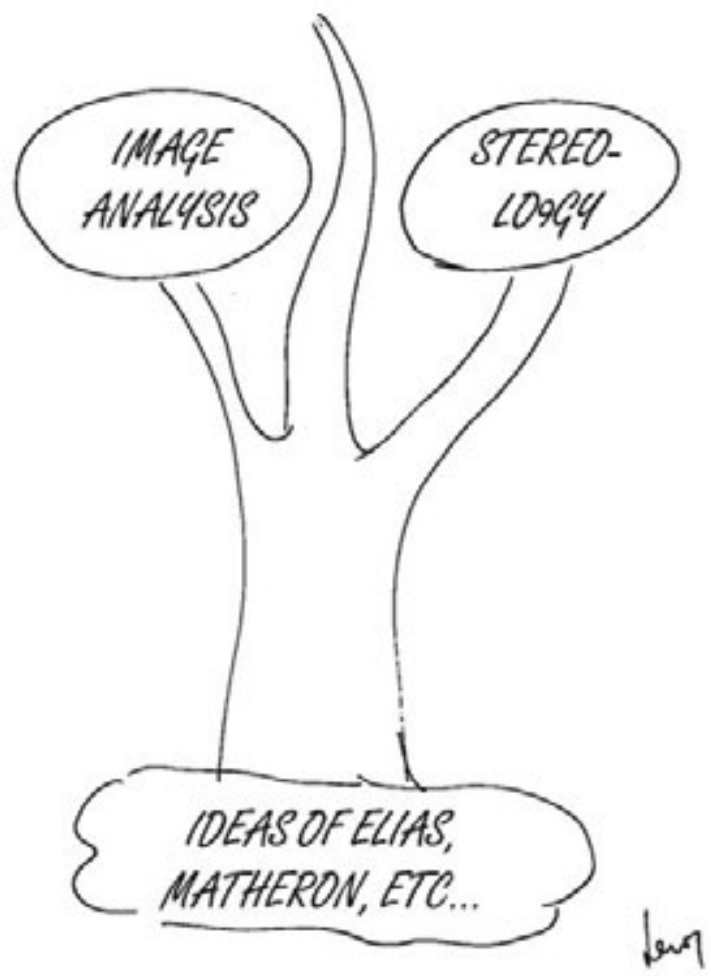

Fig. 18. This is now clear that image analysis and classical stereology are simply different branches of the same tree (8ECS\&IA, 2001).

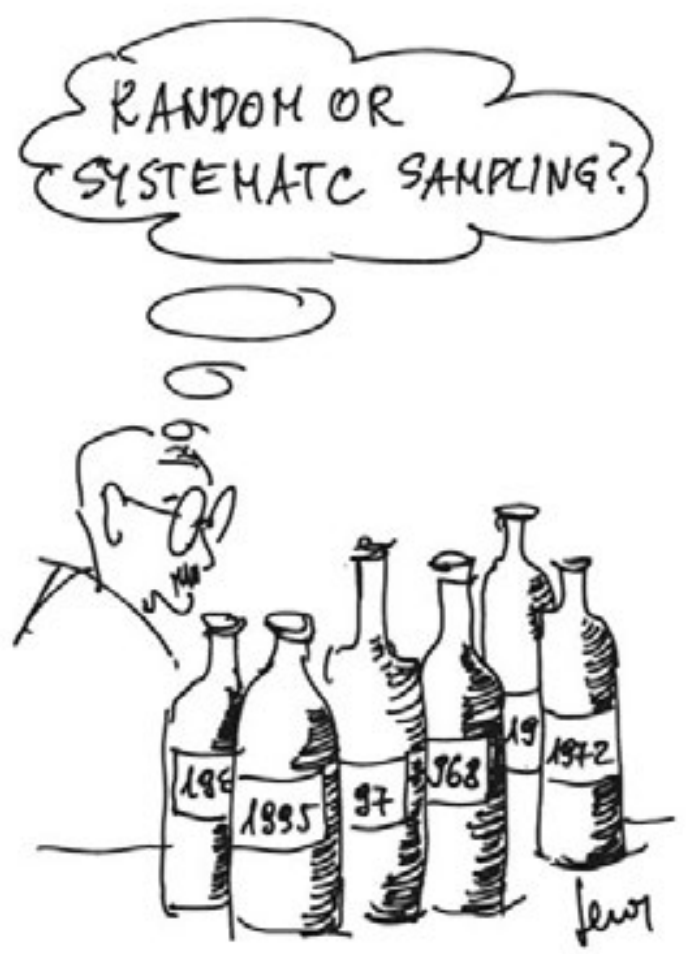

Fig. 19. This drawing is a result of the banquet in a vineyard at Saint Emillion (8ECS\&IA in Bordeaux, 2001). 


\section{ACKNOWLEDGEMENTS}

The author wishes to express his sincere thanks to Jean-Louis Chermant for encouragement and valuable discussion, suggestions and remarks that allowed improving significantly this text.

\section{REFERENCES}

ASTM E7-99 (1999). Standard terminology related to metallography, Annual Book of ASTM Standards, ASTM 03.01:28-56.

Chaix JM, Quenard D, Carbonell L, Lavialle G, Allibert CH (1992). Analysis of the conduction properties of two phase materials from image analysis methods, Proc 8ICS Irvine, CA, 1991. Acta Stereol 11(Suppl 1):539-44.

Chermant JL (1899). Les ceramiques thermomecaniques, Presses du CNRS, Paris.

Chermant JL, Wojnar L (1992). Image analysis and related techniques: who is not interested? Acta Stereol 11 (Suppl 1):15-37.

Coster M, Chermant JL (1989). Precis d'analyse d'images. $2^{\text {nd }}$ Edition. Paris: Presses du CNRS, 1989.

Cwajna J, Chrapoński J, Maliński M (1997a). Application of 3D models of materials microstructure in stereology. Proc. Int. Conf. on the Quantitative Description of Materials Microstructure, 1997; Warsaw, Poland, 27-36.

Cwajna J, Richter J, Szala J (1997b). Quantitative metallography and fractography of modern tool alloys, Proc. Int. Conf. on the Quantitative Description of Materials Microstructure, 1997; Warsaw, Poland, 125-40.

Gądek A, Wojnar L, Czerwiński E (2001). Effect of histomorphometric parameters on compression strength of vertebral bodies. Image Anal Stereol 20;1:35-9.

Goyarts-Beldstra L, Van Driel-Kulber AMJ, Ploem- Zeaaijer JJ, Ploem JF, Meyer F (1983). Leitz-TAS System of cytological specimens: the results in thousand cervical smears. Microscopica Acta 6:147-60.

Gundersen HJG, Bendtsen TF, Korbo L, Marcussen N, Moller A, Nielsen K, Nyengaard JR, Pakkenberg B, Sorensen FB, Vesterby A, West MJ (1988a). Some new, simple and efficient stereological methods and their use in pathological research and diagnosis. Acta Pathol, Microbiol Immun Scand, APMIS 96, 379-94.

Gundersen HJG, Bagger P, Bendtsen TF, Evans SM, Korbo L, Marcussen N, et al. (1988b). The new stereological tools: disector, fractionator, nucleator and point sampled intercepts and their use in pathological research and diagnosis. Acta Pathol, Microbiol Immun Scand, APMIS 96, 857-81.

Janáček J (1999). Testing anisotropy by orthogonal projections. Int. conference on Stereology, Spatial Statistics and Stochastic Geometry, S4G. Prague, Czech Republic, 1999; 119-22.

Jeulin D (1992). Multivariate random image models. Acta Stereol 11(Suppl 1):59-66.
Jeulin D (1992). Random image models for microstructure analysis and simulation. Scan Microsc 6(Suppl):121-8.

Kendall MG, Moran PAR (1963). In: Griffin C, ed. Geometrical Probability. London.

Kurzydłowski KJ, Ralph B (1995). The quantitative description of the microstructure of materials. Boca Raton: CRC Press.

Latala Z, Wojnar L (2001). Computer-aided versus manual grain size assessment in a single phase material. Material Characterization 46(2/3):227-33.

Muche L, Rother P, Friesenegger A, Geupel M (2000). Evaluation of inhomogeneities in histological structures (cartilage, retina). Image Anal Stereol 19(2):119-24.

Pirard E (1992). Roughness analysis of powders using mathematical morphology. Proc 8ICS Irvine, CA, 1991. Acta Stereol 11(Suppl 1):533-8.

Proceedings of Eigth European Congress for Stereology and Image Analysis, September 4-7, 2001, Bordeaux, France. Image Anal Stereol 20(Suppl 1):618 pp.

Proceedings of Sixth International Conference Stereology and Image Analysis in Materials Science. September 20-23, 2000, Wojnar L and Rożniatowski K, eds. FOTOBIT, Cracow 2000; 456 pp.

Russ JC (1995). The image processing handbook, $2^{\text {nd }}$ edition. Boca Raton: CRC Press.

Santalo LA (1976). Integral Geometry and Geometrical Probability: Encyclopedia of Mathematics and its Applications. Reading: Addison Wesley.

Serra J (1982). Image analysis and mathematical morphology. London: Academic Press.

Serra J (1988). Image analysis and mathematical morphology. Volume 2. Theoretical advances. London: Academic Press.

Sonka M, Hlavac V, Boyle R (1998). Image Processing, analysis and machine vision. $2^{\text {nd }}$ edition. Pacific Grove: PWS Publishing.

Stroeven P, Stroeven M (1992). Application of second order stereological method to steel wire reinforced concrete. Proc 8ICS Irvine, CA, 1991. Acta Stereol 11(Suppl 1):605-10.

Szala J (2001). Zastosowanie metod komputerowej analizy obrazu do ilościowej oceny struktury materiałów. Zeszyty Naukowe Politechniki Śląskiej, Hutnictwo z.61, Gliwice, 2001.

Tęsiorowski M, Kącki W, Zarzycka M, Jasiewicz B, Wojnar L (2001). Computer assisted analysis of bone and regenerate on radiographs taken during limb elongation. 2nd International Meeting of the ASAMI, Rome, 24-26 May 2001, Abstracts book, 130.

Udupa JK, Herman GT (2000). 3D imaging in medicine. 2nd edition. Boca Raton: CRC Press.

Weibel ER (1987). Ideas and tools: the invention and development of stereology. Acta Stereol 6(Suppl 2):2333.

Wojnar L (1998). Image analysis. Applications in materials engineering. Boca Raton: CRC Press. 
Wojnar L, Kurzydlowski KJ (2000). Analysis and interpretation. In: Practical Guide to image analysis. ASM International, Materials Park, OH, 2000, 145-202.
Wojnar L, Szydłowski L, Marek-Szydłowska T (2001). A new, other than acoustic quantification method for endocardium detection in echocardiographic images. Image Anal Stereol 20(1):27-34. 